\title{
PROGRAMA DE FORMAÇÃO CONTINUADA PARA DOCENTES DA EDUCAÇÃO SUPERIOR: UM ESTUDO AVALIATIVO A PARTIR DOS RESULTADOS DE UMA TESE
}

\author{
Sueli Petry da LuZ* \\ NEWTON CÉsAR BALZAN**
}

Recebido: 27 set. 2010

Aprovado: $01 \mathrm{dez} .2011$

\begin{abstract}
* Doutora em Educação pela UNICAMP (SP). Professora da UNIVALI - Universidade do Vale do Itajaí, Itajaí, SC, Brasil. Membro do GEPES - Grupo de Estudos e Pesquisa em Educação Superior da UNICAMP (SP). E-mail: petryluz@univali.br.

** Pós- Doutorado - Boston University, USA. Professor titular da Faculdade de Educação - PUC de Campinas; SP, Brasil. Professor Colaborador da Faculdade de Educação - UNICAMP; Assessor da Pró-Reitoria de Graduação (PROGRAD), PUC-Campinas; Pesquisador Sênior-CNPq; Consultor Ad-Hoc: UNESP, FAPESP, FAEP-UNICAMP. E-mail: nbalzan@uol.com.br.
\end{abstract}

Resumo: O objetivo deste artigo é apresentar considerações avaliativas sobre os resultados de uma tese de doutorado intitulada "Programa de Formação Continuada para Docentes do Ensino Superior: um estudo de caso", desenvolvida na Universidade do Vale do Itajaí - UNIVALI, Itajaí, Santa Catarina, e apresentada na Faculdade de Educação, da Universidade Estadual de Campinas - UNICAMP, em Campinas, Estado de São Paulo, em novembro de 2007. A metodologia utilizada na pesquisa foi um estudo de caso, por meio de narrativa. O plano de desenvolvimento do artigo está dividido em quatro partes. A primeira contextualiza a instituição e o referido Programa em sua primeira edição. A segunda apresenta a metodologia e a análise dos dados da pesquisa. A terceira parte aborda os resultados do estudo de caso. A quarta parte avalia os resultados alcançados. Ao final, efetuam-se considerações que sinalizam para a importância da continuidade de estudos, em favor do estado da arte sobre formação continuada para docentes do ensino superior, que objetive caracterizar a identidade e profissionalidade docente, em nível nacional, principalmente a partir dos saberes e fazeres desses programas.

Palavras-chave: Avaliação. Docente. Formação Continuada. Ensino Superior.

\section{CONTINUING EDUCATION PROGRAM FOR HIGHER EDUCATION TEACHERS: AN EVALUATIVE STUDY BASED ON THESIS RESULTS}

Abstract: This article offers some evaluative considerations of the results of a doctorate thesis entitled "Programa de FormaçãoContinuada para Docentes do Ensino Superior: um estudo de caso" (Continuing Education Program for Higher Education Teachers: A case study), carried out at the Universidade do Vale do Itajaí (University of Vale do Itajaí) - UNIVALI, in Itajaí, Santa Catarina, and presented at the School of Education of the Universidade Estadual de Campinas - UNICAMP, in Campinas, State of São Paulo, in November 2007. The methodology used in the research was a case study, by means of a narrative. The article is divided into four sections. The first section outlines the context of the institution that developed the Program and the Program itself in its first edition. The second presents the research methodology used and the data analysis. The third addresses the results of the case study, and the fourth section evaluates the results obtained. At the end, some considerations are made that point to the importance of further studies on the state-ofthe-art in the area of continuing education for higher education teachers, seeking to characterize the identity of the teaching professional, at the national level, particularly based on the knowledge and activities of these programs.

Key words: Evaluation. Teacher. Continuing Education. Higher Education. 


\section{INTRODUÇÃO}

Este artigo objetiva apresentar considerações avaliativas sobre os resultados de uma tese de doutorado intitulada "Programa de Formação Continuada para Docentes do Ensino Superior: um estudo de caso", desenvolvida na Universidade do Vale do Itajaí - UNIVALI, em Itajaí, Santa Catarina, e apresentada na Faculdade de Educação, da Universidade Estadual de Campinas - UNICAMP, em Campinas, Estado de São Paulo, em novembro de 2007.

Há muito que fazer nessa área de formação continuada no ensino superior, principalmente como programa assumido institucionalmente e parte integrante de calendário acadêmico. A ideia da elaboração do artigo deveu-se à observação e convicção de que, embora experiências didático-pedagógicas sejam implementadas pelas Instituições de Ensino Superior, elas acabam sendo pouco analisadas cientificamente. Esta observação ganhou reforço maior com os estudos de Bordas (2006) e Bazzo (2006). Quando se efetivou a proposta de projeto de tese para estudar o tema da pesquisa existiam, no Estado de Santa Catarina, poucas Instituições de Ensino Superior - IES - trabalhando nessa área. Ao término da pesquisa, quase todas as IES catarinenses faziam referências, em seus sites, sobre a existência de "formação continuada". Note-se que se fala em formação continuada - e não em programa de formação continuada -, outra lacuna ou indefinição que foi constatada no processo da pesquisa. Muitas Instituições de Ensino Superior - Universidades, Centros e Faculdades - já efetuaram excelentes experiências que se restringiram aos relatórios internos, com pouca valorização científica dos dados e da opinião dos participantes colhidos durante o processo, incluídos, aqui, os docentes e os gestores acadêmicos. Por gestores acadêmicos entendem-se os diretores, coordenadores de Curso, coordenadores ou articuladores pedagógicos. O interesse, na pesquisa de doutorado, envolveu o "o que mudou", isto é, os aspectos do programa de formação continuada que o professor levou para a sala de aula e que, de alguma forma caracterizou-se como mudança.

Formação de professores constitui um tema desafiador, em razão da abrangência e dos múltiplos olhares de docentes, pós-graduandos e pesquisadores interessados. Nas incursões pela revisão da literatura, observou-se que existem muitas questões a serem delimitadas na área de formação, antes de uma abordagem específica. Dentre elas foram selecionadas duas questões relevantes: Estamos falando da formação para o ensino ou para a pesquisa? De que lugar estamos falando e para quem estamos nos dirigindo? 
Tais inquietações emergem quando se fala de um programa de formação continuada para docentes do ensino superior. Esclareça-se, inicialmente, que a seleção da palavra "ensino superior" aqui é intencional, porque antes de qualquer outra função, a atividade precípua do docente é ensinar, como diz Balzan (1997). Encarando-o como um docente profissional e não como profissional docente, fica evidente que sua atividade exige cada vez mais um processo de capacitação continuada em sua prática docente, dado o avanço do mundo científico, tecnológico, social, cultural e educacional. Essas mudanças exigem posturas diferenciadas e se refletem no seu bem-estar enquanto pessoa e profissional.

A partir desses enfoques reflexivos foram selecionadas, como ideia central deste artigo, a avaliação dos resultados obtidos com a tese referente às mudanças na prática docente que podem ser atribuídas ao Programa de Formação Continuada para Docentes de Ensino Superior (doravante chamado apenas de Programa), implantado em primeira edição em 2001, na UNIVALI.

Com essa perspectiva organizou-se a estrutura do artigo em quatro partes. A primeira contextualiza a instituição e o referido Programa em sua primeira edição, objeto de estudo da pesquisa de doutorado. A segunda apresenta a metodologia e a análise dos dados da pesquisa. Na terceira apresentam-se alguns resultados obtidos. Na quarta parte tecem-se algumas considerações avaliativas a partir dos resultados finais da tese. Nas considerações finais apontam-se para a importância e a necessidade da continuidade de estudos científicos sobre essa área.

Espera-se que a socialização deste estudo subsidie outras reflexões, discussões, estudos e pesquisas na área de formação continuada, especificamente, na linha de Programas institucionais.

\section{CONTEXTUALIZAÇÃO DA UNIVALI - UNIVERSIDADE DO VALE DO ITAJAÍ E DO PROGRAMA DE FORMAÇÃO CONTINUADA PARA DOCENTES DO ENSINO SUPERIOR}

A contextualização da UNIVALI foi elaborada com base na coleta de dados junto aos setores específicos da instituição, em 2010, em Provesi (2009), e no Plano de Desenvolvimento Institucional - PDI - 2007-2011.

A Universidade do Vale do Itajaí - UNIVALI - é uma instituição de ensino superior, reconhecida pelo MEC e mantida pela Fundação Universidade do Vale do Itajaí, criada por Lei municipal. Caracteriza-se como Universidade pública 
não estatal, comunitária, filantrópica e sem fins lucrativos, de natureza beneficente, de assistência social, de direito privado, com sede e foro no Município e Comarca de Itajaí, Estado de Santa Catarina.

Em 2010, a UNIVALI completou 21 anos como Universidade e 46 como Instituição de Ensino Superior em Itajaí. Ela é uma instituição multicampi, que se distribui em seis campi ao longo do litoral centro-norte catarinense: Itajaí, Balneário Camboriú, Tijucas, Biguaçu, São José e Balneário de Piçarras, mais duas Unidades de Ensino, uma no bairro Kobrasol, em São José (Grande Florianópolis) e outra em Florianópolis. Oferece mais de 70 cursos de graduação, integrantes de diversas áreas de conhecimento e distribuídos em seis Centros de ensino: Ciências Sociais e Jurídicas; Ciências Humanas; Ciências Sociais Aplicadas - Comunicação, Turismo e Lazer; Ciências Sociais Aplicadas - Gestão; Ciências da Saúde e Ciências Tecnológicas, da Terra e do Mar. Sua oferta abrange, além dos Cursos presenciais de graduação, Cursos de tecnólogos em diferentes áreas, a distância, principalmente os da licenciatura, pós-graduação e educação básica.

Possui mais de 25 mil alunos, uma infraestrutura de 163 mil metros quadrados de área construída, com 566 salas de aulas, 397 laboratórios, 12 bibliotecas, entre as de campi e setoriais, um teatro, um Centro de Vivência, dois ginásios, duas quadras de esportes e uma piscina semiolímpica. O Colégio de Aplicação - CAU, focado na educação infantil, ensino fundamental e médio, atende a quase mil alunos em unidades instaladas nas cidades de Itajaí, Balneário Camboriú e Tijucas.

A instituição contou, até 2010/1, com mais de 1,4 mil professores, dos quais em torno de $70 \%$ possuem título de mestre ou doutor, e mais de 1,2 mil colaboradores administrativos.

Oferta, ainda, semestralmente, em torno de 40 Cursos de pós-graduação lato sensu. Em 2010/2, a pós-graduação stricto-sensu possuía nove Cursos de mestrado e três de doutorado, todos recomendados pela Coordenação de Aperfeiçoamento de Pessoal de Nível Superior (CAPES), do Ministério da Educação.

A UNIVALI tem realizado programas, projetos e ações de extensão, além de disponibilizar aos alunos oportunidades de intercâmbio, possuindo cerca de 90 acordos de cooperação firmados na América Latina, América do Norte, Europa e Ásia.

Na pesquisa, a UNIVALI também mostra sua atuação séria e comprometida com as funções básicas de uma Universidade, contando em 2010/2, dentre os cadastrados no CNPq e os institucionais, com 114 grupos de pesquisa, os 
PROGRAMA DE FORMAÇÃO CONTINUADA PARA DOCENTES DA EDUCAÇÃO SUPERIOR: UM ESTUDO AVALIATIVO A PARTIR DOS RESULTADOS DE UMA TESE

quais envolviam 620 pesquisadores e 729 alunos, dentre eles um total de 269 bolsistas, distribuídos pelos diferentes programas.

Há que se destacar que, além da Universidade, a Fundação Universidade do Vale do Itajaí mantém outras entidades, dentre as quais se destacam: o Hospital Universitário Pequeno Anjo, o Sistema Educativo de Rádio e TV UNIVALI, o Laboratório de Produção e Análise de Medicamentos (LAPAM).

É nessa Universidade que se implantou, a partir de 2001, um dos Programas assumidos institucionalmente, o Programa de Formação Continuada para Docentes do Ensino Superior da UNIVALI (doravante referido apenas como Programa), que objetiva "aperfeiçoar e atualizar os saberes da docência no Ensino Superior, pela reflexão na ação, buscando a melhoria da prática pedagógica" (UNIVALI, 2001, p. 8). Ele constitui o corolário de uma trajetória de esforço consciente da comunidade acadêmica com vistas à melhoria da qualidade de ensino. Na estrutura organizacional atual, esse Programa está vinculado à Gerência de Ensino e Avaliação, setor da Pró-Reitoria de Ensino - ProEn. A ideia da implantação do Programa surgiu como consequência das avaliações internas, principalmente a avaliação institucional e avaliações externas, cujos resultados sinalizavam, dentre muitos aspectos, para a necessidade de estruturação de um programa específico para a área pedagógica.

Com base na história da formação de docentes apresentada em Sadalla et al (2000) e Pereira (2000), pode-se dizer que a UNIVALI adotou a figura do docente profissional em contínuo desenvolvimento (década de 1990), tratando-o como um investigador permanente diante dos desafios dos saberes e fazeres que envolvem a docência. Nesse sentido, a ideia básica é a da constituição de um processo de formação crítico-reflexivo da prática do professor, entendendo-o como produtor de sua própria formação profissional e docente. (UNIVALI, 2007).

O Programa de Formação Continuada para Docentes do Ensino Superior, que é realizado a cada semestre, foi assumido institucionalmente pela UNIVALI, com base na crença de que as mudanças na docência ocorrem num movimento de ação-reflexão-ação sobre a prática docente. Ele é um espaço de integração para discussão das questões de educação superior e da prática pedagógica, onde os docentes trabalham juntos, trocam experiências pedagógicas, refletem sobre as potencialidades e fragilidades do processo de ensino-aprendizagem e da educação superior. A ênfase é a mudança de paradigma, deslocando o foco do ensino para a aprendizagem.

Os fundamentos básicos do Programa tiveram origem em Nóvoa (1995), acompanhado de outros teóricos como Schön, Zeichner, Sacristán e PérezGómez, mencionados em UNIVALI (2001). 
A metodologia do Programa de Formação Continuada para Docentes do Ensino Superior trata os professores como reconstrutores de suas próprias identidades, com atividades de intervenção focadas em três eixos fundamentais: refletir, aplicar e criar (UNIVALI, 2001, 2002).

A composição curricular desse Programa, na edição 1, foi organizada em seis unidades de estudo, iniciadas em 2001/1, estendidas até 2004. Outras edições se sucederam, estando em vigor até a presente data. A proposta visava atingir a seguinte programação: conhecimento da política institucional e organizacional da UNIVALI; a articulação do projeto pedagógico com o programa da disciplina e plano de ensino; as estratégias de ensino; a avaliação dos processos e resultados de avaliação e a pesquisa na prática pedagógica (pesquisa-ação).

Esse Programa conta com uma avaliação periódica, por meio de relatórios internos, e seus resultados são veiculados em artigos científicos. As análises da área pedagógica, focadas, principalmente, nos produtos dessa avaliação periódica, ganharam gradativamente mais adeptos, e delas resultaram estudos monográficos, pesquisas avançadas em "stricto-sensu", dentre as quais se inclui a tese de doutorado de Luz (2007), que trata das mudanças na prática docente, em sala de aula, a partir de atividades desse Programa institucional.

A mencionada pesquisa de doutorado teve como objeto de estudo o Programa de Formação Continuada para Docentes do Ensino Superior da UNIVALI, edição 1, no Estado de Santa Catarina, Brasil, observando-o, sob a forma de estudo de caso, quanto às mudanças ocorridas na prática docente em sala de aula, durante o período de sua aplicação. Não se pretendeu, com a tese, realizar uma avaliação do Programa; buscou-se, apenas, detectar as mudanças na prática docente oriundas da sua implementação. A seguir apresenta-se a metodologia de coleta, sistematização e análise dos dados da pesquisa.

\section{METODOLOGIA E ANÁLISE DOS DADOS DA PESQUISA}

A pesquisa da tese de doutorado teve um recorte histórico - 1998 a 2004 - e objetivou investigar a opinião dos docentes do ensino superior e dos gestores acadêmicos (Diretores de Centro e Coordenadores de Curso) que atuavam na Instituição e participaram do Programa - edição 1.

A população da pesquisa totalizava 1.344 participantes. O universo efetivamente pesquisado atingiu 21 gestores acadêmicos e 385 professores do ensino superior, totalizando 406 pessoas. 
A pesquisa em referência foi caracterizada como estudo de caso, respaldada por estudiosos que já trataram exaustivamente desta modalidade: Greenwood (1973), Goode e Hatt (1975), Ludke e André (1986), Bruyne, Herman e Shoutheet [19--], Triviños (1994), Bressan (2000), Santos (2002), Yin $(2002,2003)$, Mendes (2003) e Ponte (2003). A opção desse estudo decorreu dos seguintes fatores:

a) possibilidade de reflexão e estudo de uma situação particular, específica, envolvida em características amplas e complexas, como a seleção de uma entidade bem definida ou uma unidade de análise - a Instituição, no caso a UNIVALI - e, ao mesmo tempo, permitir trazer a representação singular da realidade multidimensional e historicamente situada. Esta modalidade de estudo possibilita exame e análise em profundidade, com vistas a obter uma compreensão global e integrada do processo e do objeto estudado;

b) a oportunidade de inserir formas diversificadas de coleta e análise de dados, recorrendo a diferentes instrumentos de coleta, utilizados em abordagens quantitativas e qualitativas.

A opção pela narrativa encontrou respaldo teórico em Kenski (1995), Gagnebim (1982, 1997,1999), Benjamin (1987, 1994), Cunha (1998), Larrosa e Kohan (2002), Dias e Cicillini (2003), Morais (2003) e Galzerani (2003 a, b, c, d). Das justificativas elencadas na tese, selecionou-se a que fala sobre o desafio estabelecido pela relação dialética entre narrativa e experiência profissional de 15 anos da pesquisadora, que, dadas as mútuas influências, apresentam-se tão imbricadas que se tornam parte da expressão de vida de um sujeito. Assim, à medida que se vão contando as experiências, crenças e expectativas, vai-se, ao mesmo tempo, anunciando novas possibilidades, intenções e projetos. A experiência dá sentido e significado ao escrito vivido, com vistas à "[...] deixarmos de ser o que somos para ser outra coisa, diferente do que vimos sendo" (LARROSA; KOHAN, 2002, p. 5). Há, nisso, uma construção e reconstrução do vivido e apreendido com as próprias experiências do sujeito pesquisador. "Assim, jamais se está solitário, porque o presente evoca-nos permanentemente as imagens e ideias apreendidas do passado" (KENSKI, 1995, p. 146).

Três instrumentos metodológicos foram utilizados para a coleta de dados da pesquisa: a análise documental, a entrevista e o questionário. 
A coleta de dados incluiu análise documental centrada na busca de documentos oficiais da Instituição, relativos aos materiais escritos usados como fonte de informação: relatórios, dados junto aos Setores específicos, atas de reuniões, resoluções, correspondências dos Centros e da Administração Superior da UNIVALI e materiais de publicação, tendo por base o exposto por Bardin (s.d, p. 45), Ludke e André (1986) e Nunes (2000).

$\mathrm{O}$ roteiro de entrevista foi utilizado junto a 21 gestores acadêmicos dos Centros de Educação integrantes da UNIVALI, do período de 1998-2002. Ele foi efetuado com Diretores e Coordenadores de Curso, contendo oito itens vinculados aos objetivos do estudo. Envolveram a percepção dos gestores acadêmicos sobre a Política Institucional da UNIVALI, sua caracterização e indicadores de sustentação, mudanças docentes, exemplificações que evidenciam as mudanças na prática docente, atendimento das expectativas pessoais e profissionais, atribuições de significado oriundo do Programa e percepção das especificidades que diferenciariam as áreas de conhecimento.

As entrevistas, que duraram de 50 a 90 minutos, foram gravadas com o consentimento antecipado dos participantes. Os depoimentos de cada entrevistado, agrupados por área de conhecimento, foram transcritos de acordo com cada item do roteiro. Em seguida, foi feita a análise de conteúdo, por meio de categorização similar às utilizadas no questionário, como, por exemplo: expectativas, exemplificações de mudança da prática docente. Para isso, com base em Bardin (s.d) foram selecionadas algumas das regras ajustáveis a esta pesquisa, como: preocupação com a análise da totalidade das ideias apresentadas pelo entrevistado; elementos do conteúdo da comunicação classificados uma única vez; utilização de um critério de classificação, de forma a relacionar o conteúdo da fala do entrevistado com o item do roteiro da entrevista; cuidado com algum viés, quando da associação, substituição ou exclusão de elementos da comunicação já classificados.

O questionário foi testado e retestado com 14 docentes que não participaram posteriormente da pesquisa, integrantes das mais diferentes áreas e titulação. A seis desses colaboradores, foi solicitada a análise quanto: ao entendimento; à clareza, validade e consistência do conteúdo das questões; à extensão do questionário; às inclusões para considerações relacionadas às propostas de alterações, supressões, acréscimos de conteúdo e outras ponderações a critério do docente. $\mathrm{O}$ tempo de preenchimento do questionário foi variável, durando em média 30 minutos. Desse processo resultou alteração na forma de apresentação dos itens do questionário, mantendo-se, contudo, sua essência. 
A formalização da aplicação do questionário aos docentes participantes do Programa teve, como um dos procedimentos básicos, a solicitação, por meio de ofício, da autorização e aprovação do Reitor da UNIVALI e consequente cientificação à Pró-Reitora de Ensino.

Após sua aprovação pelas instâncias competentes da Universidade, os questionários foram distribuídos nos diferentes Centros. O processo de coleta de dados foi agilizado com o apoio dos Diretores e Coordenadores de cada Curso da Universidade, resultando em percentuais de devolução do instrumento de forma mais expressivos. As 13 listagens docentes foram elaboradas em conjunto com o Departamento de Administração Docente da UNIVALI, para evitar a repetição de nome e preenchimento de questionário em mais de um Centro. Ressalte-se, ainda, que a pesquisadora teve envolvimento direto na coleta dos dados.

O questionário foi composto por itens fechados e abertos, distribuídos em três partes. A parte 1, com seis questões, tratou dos informes acadêmicos atuais, relacionados a curso de formação na graduação; curso de atuação na graduação; regime de trabalho; ano de ingresso na Instituição; titulação acadêmica e tempo de experiência do docente na UNIVALI. A parte 2 focalizou a opinião dos docentes sobre o Programa, tendo cinco questões, sendo quatro abertas e uma fechada. As questões abertas solicitaram considerações positivas e negativas, bem como as mudanças na prática docente, oriundas dos módulos de estudo. A questão fechada solicitou posicionamento sobre os significados atribuídos, decorrentes da participação no Programa. A parte 3 referiu-se à opinião sobre mudanças pessoais relacionadas ao Programa e apresentou cinco questões, sendo três abertas e duas fechadas. As questões abertas relacionaram-se às expectativas e ao papel do professor, possibilitando, ainda, que o entrevistado apresentasse sugestões ou propostas alternativas para o Programa de Formação Continuada para Docentes do Ensino Superior. As questões fechadas solicitaram indicar os fatores que concorriam para a mudança na prática docente e os tópicos que necessitariam de maior atenção, por parte da Instituição, para melhorar a prática docente.

Em síntese, a análise e a interpretação dos dados do questionário tiveram como procedimentos metodológicos nas questões abertas os seguintes:

a) leitura geral de todas as respostas, com a elaboração e listagem das ideias-síntese das respostas de cada questão, objetivando a definição e o agrupamento das categorias e subcategorias de análise por área de conhecimento; 
b) tabulação, análise e síntese dos dados mais importantes e interpretação à luz da revisão da literatura utilizada e discussão dos dados.

Algumas questões tiveram registro na Planilha Excel, como: sim, não, em parte, como no caso do levantamento da expectativa. As respostas descritivas foram agrupadas pela posição afirmativa, negativa e parcial para buscar o entendimento dos docentes sobre cada item. A maioria das questões teve registro numérico, dada a diversidade de respostas que possibilitaram agrupamentos por categorias. A seguir, foram elaboradas tabelas discriminando os aspectos relacionados aos objetivos da pesquisa. De posse delas, iniciou-se o processo de interpretação e análise dos dados e a consequente redação.

A identificação do respondente do instrumento de pesquisa foi resguardada.

A análise e a interpretação dos dados do questionário envolveram, além da distribuição por frequência e cálculos percentuais, tratamento estatístico capaz de lidar com grande massa de dados.

A metodologia de tabulação e análise dos dados foi feita utilizando a planilha eletrônica $\operatorname{Excel}^{\mathrm{TM}}$, que possibilitou a geração de tabelas e gráficos diversos, integrada com o editor de texto Word $^{\mathrm{TM}}$ e a versão 3.5 do software SPAD ${ }^{\mathrm{TM}}$ (Système Pour l'Analyse de Donneés). Para melhor entendimento do Programa, foram usados, como suporte teórico, Macedo (2001), Tarnowski (2003), Sanchez (2004), Pereira (2004) e Flores (2005).

Com essas ferramentas estatísticas, as informações levantadas com o questionário foram processadas, utilizando-se a Análise Fatorial de Correspondências Múltiplas - AFCM - denominada de metodologias multidimensionais ou multivariadas. Dentre os diversos modelos, foi usado o fatorial.

O modelo fatorial permite gerar representações simplificadas de grandes massas de informações, extraindo as principais tendências existentes nos dados e eliminando os efeitos colaterais que geralmente mascaram a percepção global do fenômeno em estudo.

A escolha dessa técnica permitiu captar a visão multidimensional do problema e gerar representações gráficas sintéticas e simplificadas de fácil interpretação, assim como reconhecer padrões diferenciais no conjunto de informações e verificar as tendências mais evidentes.

Dentre as limitações da pesquisa, destacou-se a necessidade de rememoração dos fatos e acontecimentos da época, por parte dos participantes, o que poderia não estar tão presente e, dessa forma, requerer esforço de concentração. 


\section{RESULTADOS DO ESTUDO DE CASO}

A classificação dos cursos levou em consideração as áreas de conhecimento do CNPq - Conselho Nacional de Desenvolvimento Científico e Tecnológico e os resultados evidenciaram que as áreas de Ciências Sociais Aplicadas $\left(1^{\mathrm{a}}\right)$, Ciências da Saúde $\left(2^{\mathrm{a}}\right)$ e Ciências Humanas $\left(3^{\mathrm{a}}\right)$ foram as que mais contribuíram para a pesquisa. O total dessas três áreas de conhecimento chegou a 289 questionários, atingindo $73 \%$.

Os resultados desta pesquisa da tese de doutorado, de acordo com os objetivos propostos, mostraram:

a) O Programa de Formação Continuada para os Docentes do Ensino Superior da UNIVALI, tanto na opinião dos professores como dos gestores acadêmicos, atendeu a expectativas dos docentes, o que pode ser considerado satisfatório.

A conjugação de ações administrativas, mais ações acadêmicas por parte dos gestores acadêmicos, mais Programa de Formação Continuada para Docentes de Ensino Superior constituiu um dos fatores contributivos para um sucesso considerável do referido Programa. Essas ações partiram de uma aposta institucional aliada à expectativa dos docentes no ano de implantação do Programa - 2001 - e tiveram receptividade junto à gestão universitária subsequente, garantindo-se sua efetividade e continuidade. $\mathrm{O}$ espírito e a importância do Programa tinham sido desencadeados e, hoje, constitui referência para o Estado de Santa Catarina e outros.

b) Neste estudo, são fatores que concorrem para uma mudança da prática docente, na opinião dos docentes e gestores acadêmicos: estudos avançados em Mestrado e Doutorado; participação em eventos como seminários, oficinas, fóruns, reuniões; leituras reflexivas e relatos de experiências.

Um conjunto de fatores parece estar ligado ao sucesso considerável do Programa de formação de docentes do ensino superior: uso de palestrantes de renome nacional ou internacional mesclado com docentes doutores da instituição; variedade de eventos simultâneos: oficinas, palestras, mini-cursos, reuniões grupais, relatos de experiências de ensino e outros; temas diversificados, que não sejam relacionados somente à parte didático-pedagógica, coincidindo com 0 exposto por Batista e Batista (2002). Pelas sugestões dos docentes pesquisados, há que se considerar assuntos que tenham relação com o "bem-estar docente"; oficinas culturais de integração; reconfigurações teóricas que insiram o professor em análises mais amplas da vida universitária correlacionando problemáticas do contexto da educação superior e da sala de aula. O Programa é aberto a todos os 
professores da Instituição e um espaço intencional de formação que se propôs a trabalhar concepções macro e micro da Universidade. Foram consideradas concepções de Universidade, de sociedade, de mundo e de homem, aliadas às dimensões políticas, sociais e educacionais até a dimensão da instrumentalização técnica. O Programa objetivou redimensionar conceitos e atitudes do docente universitário, fazendo-o perceber em sua identidade e profissionalização docente, o que pode ser considerado um alcance satisfatório. Estes aspectos somam-se ao já exposto por Batista (2002) e Bordas (2006).

c) $\mathrm{O}$ nível de significado atribuído pelo docente à mudança de sua prática, tendo por base os conteúdos pedagógicos, em forma de módulos de estudos, propostos no Programa de formação continuada para docentes do ensino superior, tendeu mais para a instrumentalização de estratégias de ensino e de avaliação da aprendizagem. Outra mudança de prática docente de expressiva significação e bastante citada foi a ressignificação do papel do docente na Universidade, isto é, o SER DOCENTE, quando este se descobre enquanto SER PROFISSIONAL DOCENTE DE UMA PROFISSÃO e não um PROFISSIONAL DE CARREIRA QUE ENSINA. Outra mudança bastante referenciada foi a do INTERRELACIONAMENTO PROFESSOR E ALUNO.

O investimento para a mudança da prática docente do ensino superior passa pelo eixo nuclear do movimento de "ação-reflexão-ação", caso se queira ressignificar o papel do docente em atividade de ensino e aprendizagem, o que é confirmado por Batista (2002). O descobrir-se enquanto docente passa pela identidade e profissionalização docente, caso se conceber o ser docente profissional. A formação com os docentes universitários, como diz Bordas (2006, p. 17), exige reflexão sobre "a pertinência social da educação superior e sobre seu próprio compromisso a partir da compreensão das intrínsecas relações entre educação e sociedade". Aquela autora complementa, ainda, registrando que nesse mesmo nível encontram-se a compreensão das "relações entre teoria e prática, ensino-ação-reflexão-aprendizagem e o espaço da criatividade e da invenção, componentes cada vez mais essenciais à formação do profissional para as distintas áreas de conhecimento e atuação social” (p. 17).

Quanto à posição dos respondentes - os professores e gestores universitários - em relação à diferença de posição por área de conhecimento no referido Programa, destaca-se que uma análise estatística mais aprofundada revelou que professores de tempo parcial a integral, com mais tempo de experiência na Instituição e com titulação superior a mestrado, tenderam a dar maior valorização ao Programa. Na análise multivariada, as áreas de conhecimento que revelaram tendências de maior atribuição de importância aos conteúdos 
PROGRAMA DE FORMAÇÃO CONTINUADA PARA DOCENTES DA EDUCAÇÃO SUPERIOR: UM ESTUDO AVALIATIVO A PARTIR DOS RESULTADOS DE UMA TESE

programáticos e exemplificações de mudança da prática docente, por ordem, foram: a) Linguística, Letras e Artes; b) Ciências Exatas e da Terra; c) Ciências Biológicas, Engenharias e Ciências Agrárias, Ciências da Saúde; d) Ciências Sociais Aplicadas e Ciências Humanas. Para fins de esclarecimentos, utilizouse a classificação das áreas de conhecimento do CNPq.

No entanto, quando se buscou correlacionar as variáveis de estudo e o conjunto dos 19 itens do questionário, referentes aos conteúdos trabalhados no Programa, valorando cada item de 1 a 5, com atribuição de maior a nenhuma importância ao Programa em questão, a análise fatorial de correspondências múltiplas revelou que a tendência dos professores para a valoração de significância atribuída ao Programa independe das variáveis estudadas: área de conhecimento, carga horária, titulação, experiência institucional, ano de ingresso.

Ficou evidente que a percepção dos docentes tendeu para agrupamentos de respostas, por vezes semelhantes, mas diferindo quanto à atribuição de importância, exemplificação e posicionamento crítico-reflexivo segundo as áreas de conhecimento. Conforme análise de conteúdo das questões dissertativas constata-se que os docentes pensam, absorvem e possuem grau de assimilação e valoração diferenciado dos conteúdos desenvolvidos pelo Programa.

d) Quanto às exemplificações que caracterizaram as mudanças na prática docente em sala de aula e que podem ser atribuídas ao Programa, verificou-se um número bastante significativo delas, tratadas especificamente por módulos de estudo, expressas de maneira sintética quanto à organização do plano de ensino, estratégias ou procedimentos de ensino, avaliação de aprendizagem, interação professor-aluno.

A instrumentalização, apesar de toda a crítica envolvida na racionalidade técnica, (in) felizmente é um dos aspectos que necessita atenção. Há que se ter um empenho mais especial para o atendimento dos anseios desta resolução pedagógica. Pelos resultados obtidos, há necessidade de certa atenção às instrumentações diversificadas de ensino e aprendizagem, que vão desde recursos mais simples até os mais sofisticados, como a utilização da ferramenta do tipo teleduc e outras. O posicionamento crítico-reflexivo sobre questões pedagógicas conquista espaço, à medida que os docentes vão se inserindo no movimento de "ação-reflexão-ação", de percepção e resposta a questionamentos como: $\mathrm{O}$ que realizo? Como realizo? Para que realizo determinadas ações pedagógicas? Quais resultados estão sendo alcançados?

e) Em sugestões ou propostas alternativas para melhoria do Programa, docentes e gestores acadêmicos destacaram principalmente: diagnóstico; questões de qualidade de vida do docente; pedidos de formação específica não só na parte 
pedagógica, mas também nos assuntos do Curso, da área de conhecimento ou do Centro (parte mais requerida); solicitações acentuadas em "conhecimentos práticos"; estratégias mais direcionadas ao "aprender fazendo"; maior aprofundamento em práticas interdisciplinares, transdisciplinares e multidisciplinares; maior valorização do Programa em avaliações internas da UNIVALI, ou seja, o SAPI - Sistema de Avaliação da Produção Institucional; realização de Cursos de especialização.

Outra recomendação refere-se à sistematização dos procedimentos e atividades realizadas nesses Programas de Formação Continuada para Docentes do Ensino Superior nas Universidades e Centros universitários municipais.

Algumas considerações importantes sobre a pesquisa e seus resultados envolveram: o problema da implementação de práticas docentes interdisciplinares, que requerem condições estruturais e de organização administrativa da Instituição, principalmente aquelas vinculadas a um Plano de Carreira e Salários ou destinação de carga horária; o "formador" e as habilidades e competências exemplificadoras, capazes de propiciar uma interlocução profícua com seus pares, com evidências de respeito e diálogo. Além desses, despontou uma sugestão bastante polêmica sobre Programas de formação continuada para discentes, com propostas até de temas e procedimentos de condução na Universidade.

O Programa demanda um trabalho de sensibilização docente de conquista e adesão gradativas, de transparência de propósitos, de envolvimento e participação da comunidade universitária e, principalmente, do assumir institucional. Em suma, existem elementos intermediadores entre formação pedagógica e mudanças na prática docente do ensino superior que incidem de forma determinante nessa relação. Esses elementos variam e são valorizados diferentemente de pessoa para pessoa, entre e dentro da área de conhecimento, e de instituição para instituição, necessitando de outros estudos e pesquisas, em termos de compromisso e comprometimento com a docência. Registra-se que, diante da proposta almejada e dos resultados alcançados, o Programa sinalizou possíveis melhorias em três focos: a instrumentalização em estratégias de ensino e avaliação de aprendizagem; a ressignificação do papel docente, principalmente na questão da identidade profissional docente; e, na reflexividade do trabalho docente, apesar de todas as críticas e resistências. Pode-se afirmar que, em decorrência do Programa, já houve avanços na cultura profissional docente na Instituição.

Com base nesses resultados, apresentam-se a seguir considerações avaliativas sobre os resultados obtidos. 


\section{CONSIDERAÇÕES AVALIATIVAS SOBRE OS RESULTADOS ALCANÇADOS NA TESE}

Os resultados deste estudo estão inseridos num período político que compreende a expansão das instituições de ensino superior e da matrícula de estudantes universitários, a criação de novos cursos de graduação, expansão de campi, implantação de Cursos sequenciais e conquista dos primeiros passos para avanços significativos na educação a distância. Foi nesse contexto que a tese foi desenvolvida, sendo, então, apresentadas considerações avaliativas sobre os resultados alcançados em forma de itens.

a) A UNIVALI, no Estado de Santa Catarina, dentre as Instituições integrantes do sistema ACAFE - Associação Catarinense das Fundações Educacionais - contrariando as críticas (BAZZO, 2006), preocupou-se em compatibilizar expansão e formação docente para fazer frente às mudanças e situações pedagógicas que se faziam presentes na sua prática docente. A preocupação institucional estava centrada, além da formação pedagógica da prática docente de seus professores, no reforço administrativo, por parte dos gestores universitários, com múltiplas ações que visavam à capacitação docente e à melhoria de condições de atuação na Universidade, envolvendo desde a parte físico-estrutural até a organização didático-científica e profissional. O "estar junto" com o docente em seu desenvolvimento profissional e no investimento em sua carreira profissional sinalizou positivamente para o alcance dos objetivos propostos na primeira edição do Programa. .

b) Uma Instituição de Ensino Superior séria, seja Universidade, Centro Universitário ou Faculdade, preocupa-se com a permanente e incansável luta pela qualidade de seu ensino. No entanto, ao se falar de qualidade tem-se a sensação de falar de algo abstrato, intangível, distante de nosso cotidiano. Não obstante essa abstração, qualidade de ensino constitui a meta dos diferentes tipos de Instituição de Ensino Superior. Foi em nome da qualidade de ensino que Programas se movimentaram e não foi diferente com a Universidade do Vale do Itajaí. Qualidade possui um viés "mercadológico", aliando os conceitos de eficiência, eficácia, produtividade, com a lógica da concorrência, como dizem Delpino e Balzan (2007). Associa-se e interage com múltiplas ideias relacionadas à qualidade total, qualidade de serviços, ISOs e tantas outras. Por outro lado, alertam os autores de que:

o discurso da qualidade não é inocente, dadas as condições materiais e políticas que o geram; por isso, é necessário redimensioná-lo a partir de uma dimensão crítica, tendo em vista uma política universalista, que considere os excluídos (p. 84). 
Todavia, quando se fala em qualidade no ensino superior, é normal o questionamento: de quê qualidade estamos falando? A quem serve esta qualidade? No nosso entendimento, a qualidade de ensino e/ou a melhoria dos resultados de uma gestão universitária só têm sentido se chegarem até a sala de aula, se atingirem o processo de ensino e aprendizagem e o interrelacionamento professor e aluno, e se constituírem num instrumento de construção de um profissional cidadão. Cidadão esse entendido como aquele que se especializa consoante as competências, habilidades e atitudes requeridas pelo mercado, mas, também e principalmente, por aquele profissional que colabore para a existência de um mundo mais humano, mais solidário, mais justo, mais ativo e significativo em seu tempo presente, como diz Pereira (2007).

c) Um dos pontos significativos do Programa é a solicitação de conteúdos mais específicos em relação à área de conhecimento, ao Curso ou ao Centro. É fala corrente, a necessidade de atendimento à especificidade dos Cursos e do Centro, na parte das propostas alternativas. Nesse sentido, parece constituir outro ponto contraditório: tratar formação geral ou específica. Formação geral, entendidos assuntos de diferentes áreas de conhecimento e da formação específica da área de conhecimento, para tratar assunto de interesse das disciplinas do Curso ou do Centro ou das expectativas docentes. Interessa observar que quando se aborda temas da educação específica, há solicitações de educação geral e vice-versa, como dizia a gerente de ensino e avaliação da UNIVALI. A tendência, então, seria a de buscar um equilíbrio entre os dois tipos de formação, atualmente, levados em consideração pela UNIVALI. Cabe lembrar, neste tópico, que se os professores não se sentirem partícipes do Programa, começa, na mesma medida, o distanciamento entre o que a Instituição de Ensino Superior almeja e o que os docentes efetivamente querem e fazem. Há que se ter sempre presente alguns pressupostos básicos como: atendimento às expectativas dos docentes; participação na elaboração na agenda do Programa; valorização dos saberes específicos e do conhecimento pedagógico das diferentes áreas de conhecimento; integração e troca de experiência entre os participantes; diversificação de grupos de estudo e de eventos.

d) Outro item que chamou a atenção foi a declaração de que a formação continuada para docentes do ensino superior estaria suficientemente absorvida e avançada e de que estaria no momento de se implementar um Programa de formação continuada para alunos do ensino superior. Mas, caso se levar em consideração a proposição docente, o direcionamento pode ocorrer na busca de respostas às perguntas seguintes: Que perfil de aluno busca a Universidade? Que competências, atitudes e habilidades quer a Instituição de Ensino Superior ver expressas no aluno que ingressa no ensino superior? O raciocínio avocado 
PROGRAMA DE FORMAÇÃO CONTINUADA PARA DOCENTES DA EDUCAÇÃO SUPERIOR: UM ESTUDO AVALIATIVO A PARTIR DOS RESULTADOS DE UMA TESE

pelos docentes é de que se a instituição faz exigências de um perfil docente para a Instituição, seria interessante, da mesma forma, a Universidade declarar o perfil discente que quer na Instituição de Ensino Superior e passar a requerê-lo nos concursos vestibulares ou processos seletivos. Nesta questão, parece estar envolvida uma espécie de cobrança similar e indireta ao que está sendo requerido ao professor, quanto aos requisitos de conteúdo e aspectos pedagógicos, quando do processo seletivo de docente na Instituição. E, nesse sentido, a instituição deveria ter o mesmo nível de exigência para o aluno.

Uma análise efetuada da recomendação, e que gerou polêmica entre os membros da banca examinadora, quando da defesa da tese, estaria centrada na diferenciação entre o professor que já é formado e que procede de diferentes instituições, e o aluno, ainda em formação e egresso de uma única instituição. Por outro lado, não seriam os professores responsáveis pelas diferentes disciplinas que garantiriam um tipo de formação universitária numa instituição de ensino superior? Fazendo inferências no desdobramento da sugestão dos docentes, entende-se que, possivelmente, eles estariam referindo-se às atitudes universitárias que são requeridas em todas as disciplinas, imprescindíveis ao profissional eterno pesquisador do mundo de hoje e do tipo de conhecimentos básicos relacionados a: comunicação e expressão oral e escrita por parte dos alunos; o cultivo e o desenvolvimento das habilidades intelectuais comuns às disciplinas, requeridas no ambiente universitário, como saber ouvir, falar, ler e escrever; a comunicação e atitudes científicas, conforme normas da ABNT e outras. É uma sugestão que necessitaria ser bem mais investigada.

e) A questão do formador ser um "exemplo" da prática docente em que está atuando foi veiculada nas propostas alternativas, assim como a necessidade de ter mais conhecimentos práticos. A cobrança em termos prescritivos corresponde em igual intensidade a dos alunos. A ideia de um professor sem defeitos parece retroceder a um discurso reducionista de perfeição do trabalho docente.

Outro aspecto a ser comentado, por parte de alguns docentes nessas atividades de formação continuada elevou-se muito, exigindo por parte dos formadores recursos instrucionais avançados e de última geração. Objetivando instrumentar os docentes, não só como formador para a formação continuada, mas também como professor no cotidiano de sua prática pedagógica, foram ofertadas várias oficinas referentes a: "movie maker"; "movie power point"; "webquest", "microsoftvisio" e tantas outras na mesma direção. Além da profundidade de conteúdo, a excelência em recursos audiovisuais e tecnológicos é requerida ao formador. $\mathrm{O}$ docente da instituição que se propõe a ser formador precisa estar atento a esse requisito. 
f) Uma quinta questão de avaliação oriunda da pesquisa reside no fato de que após cada evento é efetuada uma avaliação solicitando a opinião do docente numa escala semântica objetiva em termos de: "plenamente satisfatório"; "parcialmente satisfatório" e "insatisfatório" sobre: tempo destinado ao tema; nível de abrangência das discussões; profundidade dos conteúdos; inscrições on-line; infraestrutura e recursos didáticos. Na forma descritiva, há a solicitação no sentido de manifestarem como consideraram o evento de que participaram, apontando: "muito importante", "o que ficou faltando" e, ao final "indicação de temáticas". Este item final encerra uma contradição: há um espaço de opinião livre do qual o docente faz pouco uso. O que se questiona são as razões dessa atitude, pois é a oportunidade para requerer temáticas que ele gostaria de ver desenvolvidas. Por outro lado, pode-se pensar que algumas programações de eventos do referido Programa não atinjam as expectativas dos docentes. A situação permite inferir que talvez o docente participante do Programa considere perda de tempo, mormente se estiver focado apenas na pesquisa ou na extensão, relegando o ensino a um segundo plano em sua carreira profissional, o que, aliás, foi um dos pontos destacados na fundamentação teórica da tese.

Cumpre registrar, neste item, que o apoio pedagógico de cada Centro sistematiza, tabula, analisa, sintetiza e elabora um relatório final sobre a opinião de cada formulário preenchido pelo docente nesses eventos. A programação incide justamente nos tópicos apresentados. A incidência deles determina a opção pelas temáticas que serão abordadas no semestre seguinte. A programação versa sobre uma parte institucional e outras vinculadas aos Centros e que tenham relação com o planejamento do ensino, o projeto pedagógico, as estratégias de ensino e avaliação, processo de ensino e aprendizagem. Há ainda programações relacionadas a temas de educação geral focalizando diferentes tipos de assuntos como: música, cosmetologia, lazer e recreação, gastronomia, técnicas de relaxamento e outros. Cada docente tem livre opção de inscrição no evento preferido em quaisquer dos Centros da Universidade, desde que compatível com sua carga horária institucional. A obrigatoriedade de participação deve coincidir com sua carga horária semanal. Contudo, nada impede que o docente participe dos eventos ofertados nos três turnos durante uma semana em diferentes Centros. A inscrição é livre, sendo ao final do semestre distribuído certificado aos participantes e aos formadores. Os palestrantes envolvem docentes externos e internos. Os da Universidade, em sua maioria, participam como palestrantes formadores mestres e doutores a partir de convite por parte dos responsáveis pelo apoio pedagógico ou, por se oferecerem voluntariamente a ministrar Cursos, desde que sem ônus para a instituição. Atualmente, está 
sendo efetuado um levantamento de candidatos para constituir um banco de dados de formadores na instituição, o que facilitará substancialmente o processo.

g) A sexta questão de avaliação está na teoria e prática. A ideia primeira seria que o espírito prático revela-se, simultaneamente, na mesma intensidade entre alunos e professores. A reclamação dos alunos relaciona-se ao foco de utilização de determinados conteúdos programáticos na vida profissional, que não veem ou insistem em não ver. Por outro lado, os docentes também apresentaram sua preferência por questões práticas que aprendem no Programa, passíveis de utilização em sala de aula. Uma das estratégias preferidas é a oficina, que envolve o aprender fazendo. Observaram-se, igualmente, depoimentos declarando que gostam de participar de eventos que permitam efetuar transferências para a sala de aula. Essa inversão de se iniciar pela prática para chegar à teoria foi a experiência do referido Programa. Na verdade, ele começou pela visão do prático, do aplicável, da técnica, para depois se chegar à teoria. A epistemologia da prática merece atenção, principalmente, no que os professores participantes querem ou necessitam. Seria como mergulhar na problematização apresentada, para depois conseguir focalizar reflexões e teorizações mais amplas. Provavelmente, nesses Programas, seja necessário fazer uma reorganização da relação teoria/prática, invertendo a lógica de que a teoria seria o referente da prática. Como diz Cunha (2006a, p. 496) "a prática não significa a aplicação e confirmação da teoria, mas é a sua fonte" e que ela é sempre "única e multifacetada". Considerar este aspecto revelou-se importante.

h) Outro ponto a destacar como sétima questão de avaliação da tese envolve a importância da didática no processo de ensino-aprendizagem. Um discurso comum é que uma aula sem didática é bastante identificável quanto ao que não possui e o que falta fazer durante o momento da aula, no qual se processa o ensino e a aprendizagem. Não estou me referindo ao docente por vocação, dom natural ou por profissionalismo, mas sim aqueles que possuem os atributos de um professor marcante, como diz Castanho (2001). Aquele em que "[...] é possível perceber que a dimensão pessoal e a dimensão profissional se entrelaçam, fazendo um todo indivisível e responsável por uma postura admirável como professor." (p.155)

Como bem diz Cunha (2006a, p. 486): “Quem pode imaginar um professor sem conhecimentos que fazem parte do universo da didática? Como alguém pode desempenhar uma função pedagógica intencional e sistematizada, sem incorporar os saberes tão específicos da docência?"

O bom desempenho docente tem ligação com o que o professor faz e com o tipo de abordagem de ensino que adota. Seja numa visão tradicional, compor- 
tamentalista, humanista, cognitivista ou sociocultural, como destaca Mizukami (1986), a didática do professor perpassa o tipo de professor.

Existem várias ideias que necessitam ser desmistificadas quando se fala em didática, notadamente no ensino superior. E algumas desmistificações necessitam de reflexões. Elas estão associadas: a existência de um processo de linearidade ou de sequência de etapas do ensino, agregadas a um conjunto de estratégias de ensino, bastante próximas aos rótulos da tendência tecnicista; a ideia da parafernália que deve acompanhar o ensino, como se fosse obrigatório o uso de recursos audiovisuais ou tecnológicos para se ministrar uma boa aula; a um conjunto de prescrições sobre como se deve ou não proceder no ensino; a associação de que a didática dita modelos, receitas, exemplos, dentre outras.

Cunha (2006b, p. 22) corrobora essa afirmação explicando-a na perspectiva da racionalidade técnica:

Outro aspecto da desqualificação da pedagogia universitária refere-se a sua condição instrumental e não raras vezes entendida como um conjunto de normas e prescrições que, na perspectiva da racionalidade técnica, teria um efeito messiânico na resolução de problemas.

Essas desmistificações constituem um dos aspectos contraditórios referentes aos docentes participantes da formação continuada. Uns a defendem ardorosamente, considerando a formação como um período áureo, de enriquecimento intelectual e pedagógico, que traz mudanças na prática pedagógica; outros não veem nela qualquer significado e sentido, considerando-a como perda de tempo. Nossa observação sugere que as explicações para essa divergência de opinião residam na priorização dada às funções universitárias, no tocante ao ensino, pesquisa e extensão. Neste sentido, Cunha (2006b, p. 28) posiciona-se registrando que "os desafios atuais da docência universitária parecem estar requerendo saberes que até então representam baixo prestígio acadêmico no cenário das políticas globalizadas, porque extrapolam a possibilidade de quantificar produtos". No entanto,

a pouca valorização do conhecimento pedagógico na formação do professor universitário contradiz o discurso acadêmico que defende essa formação específica para os outros níveis de ensino. Vive-se uma ambiguidade sobre o que representa valor para a profissionalidade docente. (p. 23).

i) A oitava consideração avaliativa decorre desta última afirmação, pois a representação mental que o docente possui sobre o ensino tem incidência na maior ou menor valorização da formação continuada. 
Assim posto, verifica-se que o ensino, no contexto acadêmico, necessita de outro posicionamento. O ensino é coisa séria, pois dele decorre a formação profissional do aluno. É preciso ter em mente que a carreira de muitos alunos encerra-se neste patamar, apesar de se saber que um profissional necessita de permanente formação.

No entanto, e paradoxalmente, o que se observa nas instituições de ensino superior, é a relegação da atividade ensino, a um segundo plano e, por conseqüência, igual destino é dado aos conhecimentos pedagógicos. Se um professor prioriza e valoriza a função de pesquisa, o ensino deixa de ter sentido e significado no seu cotidiano.

Isto fica reforçado na afirmação de Cunha (2006b, p. 21):

A concepção da docência como dom carrega um desprestígio da sua condição acadêmica, relegando os conhecimentos pedagógicos a um segundo plano e desvalorizando esse campo na formação docente de todos os níveis, mas, principalmente, o universitário. Nessa perspectiva, como afirma Kessler (2002), a formação específica para a docência foi compreendida como desnecessária.

A característica básica inicial da UNIVALI, em seus primórdios, privilegiou o ensino em todas as suas instâncias. A sua origem e a sua história, como fundação, indicam que o ensino, nessas instituições, sempre teve lugar de destaque. Dar "boas" aulas era o foco requisitado a uma prática pedagógica. Como se defendia o respeito e o pluralismo de ideias, várias abordagens de ensino foram veiculadas no processo de Universidade e, neste sentido, valorizava-se o exercício do diferente, desde que assegurada a formação do perfil profissional de cada curso. Era comum registrar, que em Universidades municipais, a trilogia das funções de uma Universidade era trabalhar a sequência: ensino, extensão e pesquisa. Os avanços da extensão como via de mão dupla - fazer chegar seus resultados à sala de aula e à própria comunidade participante e vice-versa - ganharam reforço quando do processo de Universidade. Nas Universidades municipais, a real função da extensão era e é responder à comunidade, dado seu caráter filantrópico, incluído neste conceito a forma de prestação de serviços. Até hoje, a comunidade, já acostumada ao longo dos anos, continua a requerer da Universidade inúmeros serviços.

j) A implementação de práticas docentes interdisciplinares nas instituições de ensino superior, também destacada no estudo, é a nona consideração de avaliação e constitui um dos assuntos polêmicos. Os docentes da UNIVALI sentem que precisam de maior aprofundamento e de avanços nessa questão. 
Em geral, verifica-se que há dificuldades de entendimentos e aplicação de experiências práticas, quanto às diferenças conceituais entre: disciplina, multidisciplinaridade, pluridisciplinaridade, interdisciplinaridade e transdisciplinaridade (CERI, 1973; BORDAS, 1976; 1977; FAZENDA, 1996; 2001; SANTOS FILHO, 1999; RONCA, 2001; AUGUSTO et al, 2004; SANTOMÉ apud AUGUSTO et al, 2004). Acrescenta-se a esta constatação que muitos estudos e experiências ditas interdisciplinares podem ser incluídos como multidisciplinares ou pluridisciplinares. Por outro lado, reforça-se a necessidade de condições socioeconômicas e de trabalho, vinculadas às questões estruturais e de organização administrativa da Instituição, principalmente com referência a locais de trabalho e ao plano de carreira e salários ou destinação de carga horária (LUZ, 1982). Os docentes necessitam de reuniões, grupos de estudo e proposições de atividades conjuntas, envolvendo discussão, reflexão e elaboração de propostas, o que requer, tempo e disponibilidade. Fazer um trabalho interdisciplinar exige múltiplas atitudes, envolvendo humildade, respeito, colaboração, interação, reciprocidade e tantas outras como diz Fazenda (1996).

$\mathrm{Na}$ área da saúde, a UNIVALI possui exemplos de práticas interdisciplinares que envolvem o curso na sua totalidade ou em atividades pontuais. Mesmo com estudos já efetuados, os próprios interlocutores defendem a necessidade de maiores aprofundamentos nessa temática.

1) Como décima consideração avaliativa, registra-se que a formação de professores ou a capacitação pedagógica dos professores universitários necessita de avanços em novos estudos, o que vem a ser uma conquista e um desafio. Declara-se reforço, no final da pesquisa, no sentido de que formação de professores ou capacitação pedagógica dos professores universitários, como aspiração de uma parcela significativa do magistério superior, como diz Balzan (2003), é importante, necessária e constitui fonte inesgotável de estudo e de pesquisa no dizer de Cunha (2006a). Apesar de já existirem avanços, vale a pena recordar que o professor universitário talvez seja o único profissional do ensino superior de quem, para o exercício de funções docentes, não é exigido qualquer pré-requisito. Ainda que haja, hoje, razoáveis exigências ao ingresso dos docentes na carreira, tais como concursos públicos, processo seletivo docente com "aulas didáticas", "estágio docente" nos Programas de mestrado ou doutorado e disciplinas de Didática ou Metodologia do Ensino Superior em Cursos de especialização, tudo isso parece insuficiente e sem continuidade. Ressalte-se que, não raramente, os membros das bancas de concursos ou processos seletivos para admissão de docentes nas IES são profissionais altamente capacitados em suas respectivas áreas, mas igualmente despreparados do ponto de vista didático-pedagógico. 
PROGRAMA DE FORMAÇÃO CONTINUADA PARA DOCENTES DA EDUCAÇÃO SUPERIOR: UM ESTUDO AVALIATIVO A PARTIR DOS RESULTADOS DE UMA TESE

Na UNIVALI, os processos seletivos contam sempre com a participação de um(a) professor(a) ligado(a) à área de educação, o que já constitui um avanço considerável na área da docência. A complexidade da situação docente e discente nas IES se revela sob todos os ângulos e cresce, sobretudo, quando se considera a continuidade da expansão do ensino superior e o consequente ingresso de uma diversidade de jovens sem as condições requeridas a um estudante universitário, isto é, sem o perfil de aluno universitário que a instituição que o recebe espera. O aluno menos preparado - o que é inegavelmente reforçado com os novos tipos de ingresso, não obstante sua intenção de política afirmativa de justiça social - e a insuficiente formação didático-pedagógica de professores universitários para cumprimento do exercício docente fazem com que a educação superior se deteriore gradativamente, apresentando dificuldades concretas de dar respostas aos problemas sociais. Nesse contexto, verifica-se como indispensável que as instituições assumam a formação docente como uma política institucional, que salvaguarde condições socioeconômicas e de dignidade do trabalho docente com repercussão na história social da profissão.

m) Como décima primeira consideração avaliativa, aponta-se a atitude dos dirigentes da gestão 1998-2002 e da gestão subsequente da Universidade do Vale do Itajaí, em incluir o Programa de formação continuada como uma das suas prioridades institucionais. Ressalta-se, aqui, que esses dirigentes (reitoria, direção, coordenação de Curso e responsáveis pelo apoio pedagógico) e os docentes assumiram institucionalmente, em termos do apoio, a realização do Programa, com datas definidas constantes em calendário acadêmico, aprovado pelo Conselho de Ensino e Pesquisa, e com setores responsáveis pela implementação do Programa, a saber: Gerente de Ensino e Avaliação, vinculado à Pró-Reitoria de Ensino e setores de apoio pedagógico da Universidade.

Nesse sentido, lembra-se que a pesquisa focalizou a formação didáticopedagógica de professores universitários em uma IES municipal, sensível, compromissada e competente, que resolveu assumir estudos e pesquisas sobre as questões da prática docente e pedagógica. Além de revelar a forma como produz conhecimentos nessa área, mostra parte de suas realizações.

Uma das contribuições mais significativas da pesquisa sobre o Programa de Formação Continuada para Docentes de Ensino Superior da UNIVALI, diz respeito à importância de se considerar os saberes e fazeres dos docentes das áreas de conhecimento, em razão de suas especificidades e diferenciação de entendimentos na área pedagógica.

Algumas sinalizações, como proposta alternativa para Programas deste gênero, tornam importante considerar: 
a) Público alvo a ser atingido: professores iniciantes, professores em serviço por área de conhecimento ou todos da instituição.

b) Continuidade e articulações do Programa: na continuidade, salienta-se, com ênfase, a importância dos docentes perceberem que existe um movimento crescente de alternativas e possibilidades de novas ações didático-pedagógicas, originárias das reflexões, discussões e avanços das questões teóricas e práticas do cotidiano docente de uma edição para outra; quanto às articulações possíveis do Programa, algumas já realizadas em experiências e ressaltadas por estudiosos do assunto, destaque-se a da graduação com a pós-graduação, a dos professores mais experientes com os ingressantes, isso com o fim de propiciar o encontro da experiência de um docente profissional com aqueles que se propõem a realizar um diálogo, um aprofundamento teórico-metodológico das ocorrências do cotidiano docente.

c) Institucionalização de serviços de apoio pedagógico a docentes: esse procedimento é importante para a garantia do locus de reflexão, discussão e busca de aprimoramento de propostas alternativas da prática docente.

d) Avaliação desses Programas: apesar de já existir um movimento avaliativo nesses Programas, ao final de cada etapa, há que se deixar mais explícita a valorização das propostas dos participantes. Ouvir mais, levar mais em consideração a opinião dos docentes nesses processos, para que eles se sintam importantes e integrantes do processo, o que é vital para um sucesso satisfatório. Bazzo (2006, p. 12), fazendo referência à experiência confirmada em mais recentes bibliografias na área, apresenta uma questão fundamental:

[...] Programas de formação/profissionalização para professores do ensino superior só terão alguma chance de resultados positivos quando concebidos de forma autônoma pelos próprios interessados e forem enraizadas nas questões do cotidiano elencadas e priorizadas pelo grupo em questão.

Olhando por outro enfoque, os próprios Programas de formação de professores carecem de avaliação durante e após o processo. Além disso, faltam pesquisas que avaliem seus resultados para a vida das pessoas e do coletivo que deles participam, bem como avaliações de impacto desses Programas para mudanças pedagógicas e para a melhoria da qualidade de ensino das IES. Bazzo (2006, p. 11), fazendo uma avaliação da experiência de formação de professores do ensino superior desenvolvida na década de 1990, na Universidade Federal de Santa Catarina, registra: 
Infelizmente, nem naquele momento e nem posteriormente, foi realizado algum estudo sistemático para detectar possíveis efeitos que estes Programas possam ter provocado nas concepções de educação e no desenvolvimento de práticas docentes inovadoras entre os professores.

Esta pesquisa constituiu um esforço de estudo para diminuir a mencionada lacuna quando se propôs a identificar as mudanças da prática docente que podem ser atribuídas ao Programa de Formação Continuada para Docentes do Ensino Superior da UNIVALI. Este foi um estudo de caso e, dessa forma, seu campo das generalizações é restrito e específico. Há ciência da necessidade de muitas outras pesquisas neste sentido para que se possa construir um corpo de conhecimento científico que dê maior respaldo às iniciativas nessa área.

\section{CONSIDERAÇÕES FINAIS}

Sabendo-se da insuficiência de abordagem e de investigação sobre as experiências já efetuadas e em andamento, haveria necessidade de que um conjunto de IES aproveitasse, como objeto de análise, suas próprias experiências, não só para identificação dos seus aspectos positivos e de suas fragilidades docentes, mas para que todos pudessem conhecer e crescer com a socialização dos resultados, a fim de se identificar e fomentar uma possível identidade regional, estadual e nacional no que concerne à formação de professores. Nesse sentido, ao tratar do aproveitamento dos resultados das produções efetuadas pela própria IES, Balzan (2003, p. 52) declara, como uma das constatações resultantes de sua vivência universitária, que "as experiências potencialmente ricas para a socialização profissional [...] são subaproveitadas no meio universitário".

Finalizando, recomenda-se a institucionalização de processos de formação de professores direcionados à identidade e profissionalização docente e que sejam contínuos, sistemáticos, dialógicos e com intercomunicação e integração entre os setores administrativos centrais e setoriais das IES e os respectivos Cursos.

Espera-se que as contribuições apresentadas permitam incentivar outros estudiosos a realizarem pesquisas, para que o estado da arte na área de formação docente possa caracterizar nossa identidade enquanto região e país sobre o tema. Este é apenas um passo inicial nesta caminhada. 


\section{REFERÊNCIAS}

AUGUSTO, Thaís Gimenez da Silva et al. Interdisciplinaridade: concepções de professores da área Ciências da Natureza em formação em serviço. Ciências \& Educação, Bauru, v. 10, n. 2, p. 277-289, 2004.

BALZAN, Newton César. Do estudando ao professor universitário: caminhos para a didática do ensino superior. Revista de Educação, Campinas, v. 1, n. 3, p.7-24, 1997.

Discutindo o processo de socialização profissional. In: REALI, Aline Maria de Medeiros Rodrigues; MIZUKAMI, Maria da Graça Nicoletti. Formação de professores: tendências atuais. Reimp. São Carlos: EdUFSCar, 2003. p.48-58.

BARDIN, Laurence. Análise de conteúdo. Lisboa: Edições 70, [s.d.]. BATISTA, Sylvia Helena Souza da Silva. Formação. In: FAZENDA, Ivani (Org.). Dicionário em construção: interdisciplinaridade. 2.ed. São Paulo: Cortez, 2002. p.135-137.

BATISTA, Sylvia Helena Souza da Silva; BATISTA, Nildo Alves. A formação do professor universitário: desafios e possibilidades. In: SEVERINO, Antônio Joaquim; FAZENDA, Ivani Catarina Arantes (Orgs). Formação docente: rupturas e possibilidades. Campinas: Papirus, 2002. p.185- 205.

BAZZO, Vera Lúcia. Uma experiência de formação para professores do ensino superior. Disponível em $<\mathrm{http}: / / w w w 2 . u e r j . b r / \sim a n p e d ~ 11>$. Acesso em: 30 mar. 2006.

BENJAMIN, Walter. Infância em Berlim por volta de 1900. In: BENJAMIN, Walter. Rua de mão única. Trad. Rubens Rodrigues Torres Filho e José Carlos Martins Barbosa. São Paulo: Brasiliense, 1987. p. 71 - 142. Obras escolhidas, v.2.

. O narrador: considerações sobre a obra de Nikolai Leskov. In: . Magia, técnica, arte e política: ensaios sobre literatura e história da cultura. Trad. Sergio Paulo Rouanet e Prefácio de Jeanne Marie Gagnebim. São Paulo: Brasiliense, 1994. p. 197 - 221.

BORDAS, Mérion Campos. Currículo interdisciplinar: proposição e testagem da viabilidade de um modelo. 1976. Tese (livre-docência). Universidade Federal do Rio Grande do Sul, Porto Alegre, 1976. 
. Currículo interdisciplinar: influência dos comportamentos interativos e das atitudes frente à inovação na utilização de um modelo. Porto Alegre: Instituto Nacional de Pesquisas Educacionais; Universidade Federal do Rio Grande do Sul, 1977.

Formação de professores do ensino superior: aprendizagens da experiência. Disponível em: <http://www2.uerj.br/ anped 11>. Acesso em: 30 mar. 2006.

BRESSAN, Flávio. O método do estudo de caso. Administração on-line. v.1, n.1, jan./fev./mar. 2000. Disponível em: $<$ http://fecap.br/adm_online/ art11/flavio.htm>. Acesso em: 15 abr. 2003.

BRUYNE, Paul de; HERMAN, Jacques; SCHOUTHEETE, Marc. Dinâmica da pesquisa em Ciências Sociais: os pólos da prática metodológica. Rio de Janeiro: F. Alves, [19..].

CASTANHO, Maria Eugênia. Sobre professores marcantes. In: CASTANHO, Sérgio; CASTANHO, Maria Eugênia (Coord.). Temas e textos em metodologia do ensino superior. 2. ed. Campinas: Papirus, 2001. CENTRO DE LA INVESTIGACIÓN E INNOVACIÓN EDUCACIONALES - CERI.N. Interdisciplinaridad: problemas de enseñanza e investigación en las Universidades. Universidades, México, v. 13, n. 53, p. 204-210, jul./set. 1973.

CUNHA, Maria Isabel da. A formação de professores como problema: natureza, temporalidade e cultura. Cadernos de Educação, Pelotas, n. 27, p. 55-71, jul./dez.2006 a.

\section{CUNHA, Maria Isabel da. O professor universitário na transição de} paradigmas. Araraquara: JM Ed., 1998.

CUNHA, Maria Isabel da. A Universidade: desafios políticos e epistemológicos. In: CUNHA, Maria Isabel (Org.). Pedagogia universitária: energias emancipatórias em tempos neoliberais. Araraquara: Junquiera\&Marian, 2006b.

DELPINO, Rosemar; BALZAN, Newton. Educação superior: a qualidade total em questão. Avaliação, Campinas, v. 12, n. 1, p. 73-89, mar. 2007.

DIAS, Fátima Rezende Naves; CICILLINI, Graça Aparecida. Pela narrativa dialógica: os movimentos de constituição de formação de professores a partir do interior da escola. Disponível em: <http:www.anped.org.br/25/posteres/ fatimarezende_navesdiasp.08.rtf>. Acesso em: 28 ago. 2003. 
FAZENDA, Ivani Catarina Arantes. Integração e interdisciplinaridade no ensino brasileiro: efetividade ou ideologia. 4.ed. São Paulo: Loyola, 1996. . Dicionário em construção: interidisciplinaridade. São Paulo: Cortez, 2001.

FLORES, Luiz Carlos da Silva. Fatores de gestão que influenciam o desempenho das universidades comunitárias do sistema fundacional de ensino superior de Santa Catarina. 2005. 175f. Tese (Doutorado em Engenharia de Produção) - Programa de Pós- Graduação em Engenharia de Produção, Universidade Federal de Santa Catarina, Florianópolis, 2005.

GAGNEBIN, Jeanne Marie. Walter Benjamin. São Paulo: Ed. Brasiliense, 1982.

. Sete aulas sobre linguagem: memória e história. Rio de Janeiro: Imago, 1997.

Perspectiva, 1999.

. História e narração em Walter Benjamin. São Paulo:

GALZERANI, Maria Carolina Bovério. Memória, história e (re) invenção educacional: uma tessitura coletiva na escola pública. Campinas: UNICAMP, 2003a. (Mimeo)

Walter Benjamin : Disciplina Memória, Modernidade Capitalista e Educação. Curso de Pós - Graduação em Educação, Faculdade de Educação, UNICAMP, 11 de set. a 11 dez. 2003b. 42 f. Notas de aula.

. A tessitura do conhecimento histórico e suas relações com a literatura. Campinas: Faculdade de Educação da UNICAMP, 2003c. (Mimeo).

. A narrativa em Walter Benjamin. Campinas: Grupo FORMAR - Ciências, Faculdade de Educação Universidade Estadual de Campinas, 2003d. 2 fitas cassetes (210 minutos). Transcrição de Sueli Petry da Luz.

GOOD, William J.; HATT, Paul K. Métodos em pesquisa social. 5. ed. São Paulo: Ed. Nacional, [1975].

GREENWOOD, Ernest. Metodologia de la investigacion social. Buenos Aires: Paidos, 1973.

KENSKI, Vani Moreira. Sobre o conceito de memória. In: FAZENDA, Ivani (Org.). A pesquisa em educação e as transformações do conhecimento. Campinas: Papirus, 1995. p. $137-159$. 
PROGRAMA DE FORMAÇÃO CONTINUADA PARA DOCENTES DA EDUCAÇÃO SUPERIOR: UM ESTUDO AVALIATIVO A PARTIR DOS RESULTADOS DE UMA TESE

LARROSA, Jorge; KOHAN, Walter. Apresentação da coleção. In: RANCIÈRE, Jacques. O mestre ignorante: cinco lições sobre emancipação intelectual. Belo Horizonte: Autêntica, 2002. p 5.

LÜDKE, Menga; ANDRÉ, Marli E.D.A. Pesquisa em educação: abordagens qualitativas. São Paulo: EPU,1986.

LUZ, Sueli Petry da. A atitude dos professores de ensino superior frente aos fatores que condicionam a implementação de um tipo de experiência interdisciplinar: um estudo descritivo. 1982. 116 f. Dissertação (Mestrado em Educação) - Cursos de Pós-Graduação em Educação, Universidade Federal de Santa Catarina, Florianópolis, 1982.

. Formação continuada para docentes da educação superior: um estudo de caso. 2007. 227p. Tese (Doutorado em Educação), 2007. Programa de Pós-Graduação em Educação, Faculdade de Educação, Universidade Estadual de Campinas, Campinas, 2007.

MACEDO, Sandré Granzotto. Desempenho docente pela avaliação discente: uma proposta metodológica para subsidiar a gestão universitária. 2001. 132 p. Tese (Doutorado em Engenharia de Produção) - Universidade Federal de Santa Catarina, Florianópolis, 2001.

MENDES, José Carvalho. A abordagem qualitativa e quantitativa no estudo de caso. Disponível em: <http: // qofisb.dei.uc.pt/capsi2002/ worksshop/cãs/3jose.Mendes.pdf>. Acesso em: 11 abr. 2003.

MIZUKAMI, Maria da Graça Nicoletti. Ensino: as abordagens do processo. São Paulo: EPU, 1986.

MORAIS, Jacqueline de Fátima dos Santos. Algumas notas a respeito do estilo de escrita em "Infância em Berlim por volta de 1900", de Walter Benjamin. Disponível em : <http://www.filologia.org.br/venlf/anais\%20v/ civ10_02.htm>. Acesso em: 12 dez. 2003.

NÓVOA, António. A formação de professores e profissão docente. In:

NÓVOA, António (Coord.). Os professores e a sua formação. Lisboa: Dom Quixote, 1995. p. 15-33.

NUNES, Cely do Socorro Costa. Os sentidos da formação contínua de professores. O mundo do trabalho e a formação de professores no Brasil. 2000. 152 f. Tese (Doutorado em Educação) - Faculdade de Educação, UNICAMP, Campinas, 2000. 
PEREIRA, Júlio Cesar Rodrigues. Análise de dados qualitativos: estratégias metodológicas para as Ciências da Saúde, Humanas e Sociais. 3 ed. 1. reimpr. São Paulo: EDUSP, 2004.

PEREIRA, Elisabete Monteiro de Aguiar (Org.). Universidade e educação geral: para além da especialização. Campinas: Alínea, [2007]. (Coleção Educação em Debate).

PEREIRA, Júlio Emílio Diniz. Formação de professores: pesquisas, representações e poder. Belo Horizonte: Autêntica, 2000.

PONTE, João Pedro da. O estudo de caso na pesquisa em Educação Matemática. Disponível em: $<$ http:// educ. fc.ul.pt/docentes/ jponte / docspt/ 94-Ponte (quadrante-estudo-caso) doc>. Acesso em: 15 abr. 2003.

PROVESI, José Roberto. Universidade Do Vale do Itajaí: papel preponderante no desenvolvimento do Litoral Centro-Norte de Santa Catarina. In: SCHMIDT, João Pedro (Org.). Instituições comunitárias: instituições públicas não-estatais. Santa Cruz do Sul: EDUNISC, 2009. 1 CD-Rom. p. 356-361.

RONCA, Paulo Afonso. O conhecimento total. Revista Nova Escola: a revista do professor, São Paulo, v. 19, n. 148, dez. 2001.

SANCHEZ, E. N. Organização e Carreira: padrões de comportamento de docentes universitários e relação com o desempenho no ensino. 2004. 226 f . Tese (Doutorado em Engenharia de Produção: Ergonomia) - Universidade Federal de Santa Catarina, Florianópolis, 2004.

SADALLA, Ana Maria Falcão de Aragão et al. Teorias implícitas na ação docente: contribuição teórica ao desenvolvimento do professor práticoreflexivo. In: AZZI, Roberta Gurgel; BATISTA, Sylvia Helena Souza da Silva; SADALLA, Ana Maria Falcão de Aragão. Formação de professores: discutindo o ensino de Psicologia. Campinas: Ed. Alínea, 2000. p. 21-38.

SANTOS FILHO, José Camilo dos. A interdisciplinaridade na universidade: perspectiva histórica. Educação Brasileira, Brasília, v. 21, n. 43, p. 11-47, jul./dez.1999.

SANTOS, Gildenor Carolino. Estudo da interlocução entre biblioteca - escola - tecnologia, baseada na Internet: um estudo de caso na Escola Estadual Sérgio Pereira Porto. 2002. Dissertação (Mestrado) - UNICAMP, Campinas, 2002. 
TARNOWSKI, Washington Luiz. Análise exploratória de dados: relacionamento entre o desempenho docente e o Exame Nacional de Cursos. 2003. 83 p. Dissertação (Mestrado em Engenharia de Produção) Universidade Federal de Santa Catarina, Florianópolis, 2003.

TRIVIÑOS, Augusto N. S. Introdução à pesquisa em ciências sociais: a pesquisa qualitativa em educação. São Paulo: Atlas, 1994.

UNIVALI - Universidade do Vale do Itajaí. Pró-Reitoria de Ensino. formação continuada para docentes do ensino superior: curso de atualização pedagógica presencial. Itajaí: UNIVALI. 2001.

. Formação continuada para docentes do ensino superior:

apontamentos para novas alternativas pedagógicas. Coords. Amândia Maria de Borba; Sueli Petry da Luz. Itajaí: UNIVALI, 2002.

. Pró-Docência: Guia 2007. Itajaí: UNIVALI, 2007.

Itajaí:UNIVALI, 2009.

. Plano de Desenvolvimento Institucional 2007-2011.

. Dados da Biblioteca Central e dos Setores de Pesquisa e PósGraduação. Itajaí: UNIVALI, 2010.

YIN, Robert K. Estudo de caso: planejamento e métodos. Tradução de Daniel Grassi. reimp. Porto Alegre: Bookman, 2002 .

. Case study research: design and methods. Tradução de Ricardo Lopes Pinto. Disponível em: <http://eac.fea.usp.br/metodologia/estudo-caso. asp.>. Acesso em: 15 abr. 2003 